\title{
O que dizem os professores sobre o sistema de cotas para negros nas universidades públicas
}

Lorene dos SANTOS*

Lana Mara de Castro SIMAN**

\section{RESUMO}

Este trabalho apresenta uma análise do conteúdo de um fórum de discussão, em meio virtual, onde um grupo de professores de uma rede pública de ensino, em Minas Gerais expressou, sob a forma de depoimentos, opiniões e posicionamentos, suas representações e saberes acerca do tema "cotas para negros em universidades públicas brasileiras". Para melhor compreender o que dizem os professores acerca deste tema traçamos, inicialmente, um brevíssimo panorama das discussões envolvendo a questão racial em nosso país para, em seguida, identificar e problematizar os argumentos que apóiam os posicionamentos dos professores, assim como os pontos sobre os quais se situam alguns dos embates, tensões e polêmicas em torno dessa questão.

Palavras-chave: representações, saberes docentes, cotas raciais, educação antiracista.

Nas últimas décadas, vimos ampliar o debate sobre o racismo e a posição dos afro-descendentes na sociedade brasileira, ao mesmo tempo em que se multiplicam ações de combate ao preconceito e diferentes formas de discriminação racial, ainda presentes em nossa sociedade. A discussão sobre a implementação das chamadas ações afirmativas, em especial o estabelecimentos de cotas para negros em universidades públicas brasileiras, vem ocupando cada vez mais espaço nos meios de comunicação de massa e em diferentes instâncias da vida social. Para além das projeções que acompanham tanto os

* Graduada em História pela UFMG; Doutoranda em Educação pela UFMG; Professora da PUC Minas; Assessora de História do CEFOR PUC Minas.

** Doutora em Didática da História pela Universidade de Laval, Canadá. Professora do Programa de PósGraduação em Educação da UFMG; Assessora Pedagógica do CEFOR PUC Minas. 
argumentos favoráveis quanto aqueles contrários às cotas e demais ações afirmativas trabalhamos com a hipótese de que este processo tem possibilitado uma maior mobilização da sociedade brasileira diante da questão racial, potencializando a discussão sobre a crença de que seríamos uma sociedade marcada por maior tolerância racial, por um racismo considerado "mais brando", ou como nos acostumamos a nomear, por uma "democracia racial".

0 impacto causado pelo anúncio e o início do processo de implementação de cotas raciais em algumas universidades brasileiras vem provocando, assim, uma nova configuração do debate, instigando o posicionamento de diferentes sujeitos e promovendo, em alguns casos, polêmicas e discussões acirradas. Para muitos brasileiros, essa discussão é uma novidade e não são poucos os que estão começando a refletir e a construir posicionamentos a esse respeito, muitas vezes instigados por situações formais de debate ou por se depararem com a questão em suas experiências cotidianas. 0 que dizem os professores $\mathrm{da}$ educação básica a esse respeito? Onde se situam os pontos polêmicos, os pontos de embate, as concordâncias? Qual o potencial educativo desse debate? Nesse artigo, nos debruçaremos sobre essas questões com base em estudo exploratório junto a professores da educação básica que trabalham na rede pública municipal de Contagem, Minas Gerais.

\section{0 debate em torno da questão racial na sociedade brasileira.}

0 debate envolvendo o tema "raça", em nosso país, ainda que pareça incipiente para a maioria da população é bem mais antigo e já assumiu configurações bastante diversas, ao longo da história brasileira. Embora 0 pensamento racial brasileiro nunca tenha sido homogêneo, sua trajetória histórica incluiu, necessariamente, alguns temas e momentos especialmente significativos que merecem ser recuperados para situar o debate e as ações políticas contemporâneas. Destacam-se as primeiras interpretações nativas do chamado "racismo científico", no século XIX e o ideal de branqueamento da população, que ajudou a difundir . 0 surgimento do mito da "democracia racial", nos anos 30 do século XX, e seu posterior desmantelamento, no plano da pesquisa acadêmica, ocorrido a partir dos anos 1950, através dos ciclos de estudos patrocinados pela UNESCO ou desenvolvidos no âmbito do convênio 
Estado da Bahia - Columbia University constitue um outro momento que delimita o campo dos embates políticos em torno das questões que envolvem a questão do racismo no Brasil.

No âmbito das primeiras pesquisas em torno da questão racial brasileira um dos principais expoentes da chamada "escola paulista"1, 0 sociólogo Florestan Fernandes, identificou uma importante especificidade de nosso racismo, sistematizada por ele como o "preconceito de ter preconceitos". Desde então, diversos estudiosos têm se dedicado à tarefa de mapear e compreender as diferentes formas de preconceito e discriminação raciais presentes na sociedade brasileira. De acordo com SCHWARCZ (2006, 44), "o uso privado do racismo, a manipulação social da raça e das cores, uma mestiçagem avançada, mas, também, um claro processo de exclusão social" caracterizam uma forma de racismo bastante peculiar, que a autora chama de "racismo à brasileira".

É bem verdade que 0 intenso processo de mestiçagem de nossa história gere dúvidas sobre quem é negro no Brasil e seja evocado como argumento para negar ou relativizar a existência do racismo brasileiro. No entanto, é notória a exclusão que se dá por critérios raciais, e não apenas sócio-econômicos. Ela se evidencia em dados estatísticos sobre 0 acesso à educação, lazer, saúde e condições de saneamento básico, na expectativa de vida, nos índices de mortalidade infantil, na distribuição desigual de renda e de bens culturais produzidos pela sociedade, dados estes em que a população negra aparece em posição desfavorável, evidenciando a ausência de uma distribuição equiitativa dos direitos. ${ }^{2}$

Identificado nas pesquisas acadêmicas desde os anos 1950, o racismo brasileiro começou a ganhar maior visibilidade social a partir de fins dos anos 1970, no bojo do processo de (re)democratização da sociedade brasileira, onde, em meio efervescencia dos movimentos sociais, o movimento negro despontou como um dos

10 ciclo de estudos patrocinados pela UNESCO ou desenvolvidos no âmbito do convênio Estado da Bahia Columbia University, costuma ser identificado por duas grandes escolas: a "escola baiana", que reúne intelectuais da Bahia, Recife e norte do Brasil; e a "escola paulista", reunindo intelectuais de São Paulo, Rio de Janeiro e sul do Brasil. Embora sejam tradicionalmente apontadas diferenças de interpretações entre as chamadas "escolas baiana e paulista", identificando-se, na escola baiana, uma maior continuidade das análises anteriormente formuladas por Gilberto Freyre e Donald Pierson, pautadas no conceito de democracia racial, Guimarães (2005) defende que o consenso entre estudiosos de ambas as "escolas" acerca da existência do preconceito racial no Brasil era muito maior do que se supõe.

2 A esse respeito, ver, por exemplo, o Atlas Racial Brasileiro 2005, uma publicação do Programa das Nações Unidas para 0 Desenvolvimento - PNUD, disponível em http:/www.pnud.org.br/publicacoes/atlas_racial/index.php. 
importantes veículos de denúncia do racismo e de reivindicação de igualdade real e não apenas formal - de direitos. Multiplicando-se em organizações e atividades variadas, os movimentos de afirmação da identidade negra vêm ocupando importante espaço na sociedade brasileira, inclusive em instâncias oficiais, que especialmente na última década, passaram a contar com a presença de diversos militantes e intelectuais engajados na luta anti-racista.

0 conceito de "democracia racial", freqüentemente evocado por diferentes forças sociais e polemizado no âmbito acadêmico, parece ainda manter um certo poder de convencimento. No entanto, não se pode negar os avanços verificados nas últimas décadas, quando a questão racial vem ocupando cada vez mais espaço nos debates ocorridos em diferentes instâncias sociais, passando a ser reconhecida como um dos grandes desafios a serem enfrentados pela sociedade brasileira e contribuindo, assim, para abalar a tradicional certeza de sermos um "paraíso racial".

No âmbito da educação formulam-se uma política educacional e uma legislação específica voltada para a valorização da diversidade étnico-cultural e para o empreendimento de uma educação anti-racista. Como exemplos, podemos citar a Lei de Diretrizes e Bases da Educação Nacional - LDBEN 9.394/06, os Parâmetros Curriculares Nacionais - PCN, e mais recentemente, a obrigatoriedade do ensino de história e cultura africana e afro-brasileira na educação básica, a partir da Lei 10.639/0333, cujas "Diretrizes Curriculares" que a acompanham, trazem a ênfase na promoção de uma educação das relações étnico-raciais. Esse conjunto de políticas e, ainda, a perspectiva de estabelecimento do sistema de cotas para negros em universidades públicas brasileiras, vem contribuindo para o engajamento de diferentes sujeitos e instituições na discussão acerca da "questão racial", em nosso país, com a emergência de diferentes argumentos e posicionamentos sobre o tema.

\section{Cotas para negros nas universidades públicas: argumentos e controvérsias}

Antes de apresentarmos os posicionamentos e argumentos mobilizados por professores de um sistema público de ensino acerca do sistema de cotas

\footnotetext{
3 Uma nova lei foi recentemente promulgada, a Lei 11.645/08, incluindo, como conteúdo obrigatório, além da temática africana e afro-brasileira, a questão indígena.
} 
para negros em universidades públicas, vale a pena sintetizarmos alguns dos pontos em torno dos quais tem girado a controvérsia atual, em nosso país, e que dizem respeito a: se as cotas ferem ou não o princípio de igualdade perseguido desde a época moderna e consolidado na legislação atual, cujo principal exemplo seria a própria Constituição Brasileira; se as cotas ferem 0 princípio do "mérito individual" e qual o lugar deste princípio na busca por uma sociedade mais justa e democrática; sobre as dificuldades em se definir os beneficiários dessa política em um país profundamente miscigenado como 0 nosso; associado a este aspecto, o dilema de se reforçar o conceito de "raça" (talvez um dos pontos mais polêmicos entre os partidários de cada posicionamento); outra questão diz respeito ao risco de estigmatização da população beneficiada, que poderia ser alvo de um acirramento de preconceitos; por fim, uma das questões centrais gira em torno da polêmica entre cotas raciais ou cotas sociais, que levam a uma discussão sobre justiça social e inclusão de outros grupos marginalizados (os brancos pobres, indígenas, etc.). Muitas dessas questões podem ser sintetizadas na polêmica entre a priorização de políticas universalistas X políticas particularistas, desdobrando-se em uma série argumentos arrolados por ambos os lados.

Vale lembrar que em ambos os posicionamentos - favoráveis ou contrários - encontramos alinhamentos que apelam para princípios assentados, ora em perspectivas liberais, ora em perspectivas socialistas de rompimento das hierarquias e desigualdades sociais, muitas vezes permeados por contradições e paradoxos. Não é por acaso que encontraremos posições diferenciadas entre políticos, intelectuais e até mesmo entre militantes do movimento negro. Essa questão, entretanto, ainda causa certo "mal-estar" entre os debatedores, como se pode perceber pela fala de Célia Azevedo (2004), em artigo em que assume posição contrária às cotas raciais:

Nesse debate, a questão assume uma conotação divisora entre esquerda e direita. É comum que quem defende a cota racial se julgue de esquerda e diga que os outros são de direita. Quem ousa se colocar contra a cota racial, defende-se como pode para afastar de si o jargão de direita e pior ainda, o de racista.

Atentos a esse risco, ao nos debruçarmos sobre os depoimentos apresentados pelos professores pesquisados, também procuramos evitar 
julgamentos e classificações precipitadas. Em ambos os posicionamentos, encontraremos argumentos que remetem a concepções diferenciadas de sociedade e a projetos de futuro também diversos.

Interessa-nos, portanto, neste trabalho, flagrar um momento de debate que extrapola algumas das instâncias tradicionalmente mais atuantes no debate público - academia, grande imprensa, militância e instituições políticas procurando compreender alguns dos saberes e representações que sustentam os argumentos e posicionamentos arrolados por um grupo de professores de uma rede pública de ensino, no âmbito de um processo de formação continuada. Obviamente, os professores pesquisados são profundamente marcados pelo debate público e o presente trabalho traz evidências de como esses sujeitos se apropriam e reinterpretam alguns dos argumentos mais comuns que têm circulado na arena social, sejam eles favoráveis ou contrários ao estabelecimento de cotas para negros em universidades públicas 4 .

\section{0 sistema de cotas para negros em debate: 0 que dizem os professores}

É importante destacar que se trata de uma análise preliminar, realizada a partir de pesquisa exploratória, que teve como fonte o conteúdo de um fórum de discussão, desenvolvido em meio virtual, entre professores de educação básica que trabalham na rede pública municipal de Contagem, Minas Gerais. Tal fórum foi parte das atividades propostas pelo curso de formação continuada de professores, intitulado "Ensino de História e Cultura Africana e Afrobrasileira”, ministrado pelo CEFOR PUC Minas". 0 Fórum em questão estendeuse de 13 de fevereiro a 19 de março de 2007 e contou com 190 participações ${ }^{6}$, tendo a seguinte dinâmica de funcionamento: a partir de uma questão, de

\footnotetext{
4 Para subsidiar a discussão, foram disponibilizados, no ambiente virtual do curso, alguns endereços de sites com textos e depoimentos de diferentes atores sociais sobre o tema das cotas.

50 Centro de Formação Continuada de Professores - CEFOR PUC Minas compõe a Rede Nacional de Formação Continuada de Professores, um projeto do MEC, através de sua Secretaria de Educação Básica, que tem como objetivo sistematizar e expandir a formação continuada de professores da educação básica. 0 curso em questão foi ministrado entre os meses de outubro de 2006 e março de 2007, na modalidade à distância (contando com dois encontros presenciais), com uma carga horária de 120 horas.

6 Ao todo, identificamos a participação de 132 professores, com formações variadas e atuando em diferentes níveis da educação básica. Alguns deles participaram mais de uma vez, além de serem contabilizadas 20 intervenções/participações da equipe pedagógica.
} 
caráter provocativo, descrita abaixo, os professores postaram suas opiniões e depoimentos, debatendo entre si e com a equipe pedagógica do curso ${ }^{7}$, suas representações e saberes acerca do estabelecimento de cotas para alunos negros nas universidades públicas brasileiras.

Questão proposta:

Caros (as)alunos (as),

0 estabelecimento de cotas para alunos negros nas universidades públicas brasileiras está na pauta do dia. Tal política tem por princípio o combate à discriminação racial, expressa no reduzido acesso desse grupo à educação superior. Ao mesmo tempo, o sistema de cotas acarreta um certo tipo de discriminação, conhecido como discriminação positiva. Com a identificação dos estudantes racialmente excluídos, definem-se os beneficiários dessa ação.

Apresente o seu posicionamento sobre a questão acima, procurando fundamentar seus argumentos. Para tanto, você pode recorrer às indicações de sites disponíveis no final do Cd-rom e no Centro de Recursos.

Contamos com a participação de todos.

Equipe de Coordenação

Não foi objetivo desta pesquisa contabilizar os posicionamentos favoráveis e/ou contrários ao estabelecimento de cotas para negros em universidades públicas, mas vale a pena destacar que diversos professores posicionaram-se claramente a esse respeito, enquanto inúmeros outros optaram por traçar um balanço dos argumentos favoráveis e contrários às cotas, identificando vantagens e desvantagens em ambos.

Um dos pontos mais destacados pelos professores, em qualquer dos grupos, foi a necessidade de melhoria da educação básica pública brasileira. Inúmeros professores mostraram-se não apenas preocupados com a atual situação do ensino público, mas evidenciaram uma aposta neste, enquanto veículo de promoção de oportunidades e de combate à brutal desigualdade que prevalece em nossa sociedade:

7 A equipe pedagógica foi composta por uma coordenação geral, uma coordenação acadêmica, duas professoras e 19 tutores, todos formados em História ou Geografia. Uma das autoras deste trabalho atuou como Coordenadora Acadêmica do curso. 
Se esta educação pública não está boa, é necessário que ela seja modificada, tenha mais recursos, mais estrutura, tenha professores bem qualificados e remunerados. Assim esta escola vai estar preparada para capacitar o aluno a entrar na universidade sem a necessidade de um sistema de cotas. ${ }^{8}$

É necessário que os governos [...] realmente entendam que através da educação de qualidade e disponível para todas as camadas da sociedade que teremos a oportunidade de observar uma competição saudável em busca dos bancos das universidades.

Muitas falas em defesa da escola pública parecem assentadas na perspectiva de que políticas universalistas - de garantia de direitos fundamentais a todos os cidadãos - seriam o melhor caminho para resolver, num certo prazo de tempo, as desigualdades raciais.

[...] idealizo um projeto bem maior, para resolver, não só a polêmica das cotas, do racismo, mas também da pobreza. Penso que devem ser construídas, urgentemente, políticas de combate a desigualdade social e, paralelamente de valorização das culturas ditas periféricas $[\ldots]$

[...] Insisto que o ideal para nosso país é promover uma política educacional voltada para a igualdade de direitos, possibilitando a todos o acesso a educação. [...] .Se isto ocorrer certamente veremos um maior número de negros e pardos nos bancos de escola, pois a maioria da população carente do país teria condições de entrar e permanecer na escola.

Guimarães (2005), um dos autores que se posiciona favoravelmente ao estabelecimento de cotas raciais, argumenta que tal crença não tem se confirmado, mesmo em países onde tais políticas já se encontram bastante consolidadas, como é o caso dos Estados Unidos, onde medidas universalistas não conseguiram romper os mecanismos inerciais de exclusão racial. Por outro lado, diversos opositores das cotas raciais, mesmo reconhecendo que o preconceito racial não seria

8 Todas as falas não identificadas são de professores que participaram do fórum de discussão, cujo conteúdo constitui o material empírico que serviu de base às análises empreendidas neste trabalho. 
automaticamente superado com o combate à desigualdade social, indicam sua priorização como mais relevante ou urgente, sobretudo em se tratando de uma sociedade tão profundamente desigual como a nossa.

A defesa de políticas universalistas em lugar das cotas raciais tem comparecido tanto em perspectivas pautadas por uma concepção liberal de igualdade de oportunidades, quanto em perspectivas pautadas por uma concepção mais ampla de justiça social. Dentro desse último grupo encontramos aqueles que defendem a idéia de que o Estado - como governo - não deveria promover particularismos nem tampouco conceber a sociedade de maneira dividida ou desigual ${ }^{9}$, sobretudo levando-se em consideração a necessidade de combater práticas personalistas, clientelistas e particularistas que fazem parte da tradição brasileira.

Assim, no âmbito da polêmica entre políticas universalistas X particularistas, se encontram diferentes interpretações para o legado da luta pela igualdade. Tal legado se encontra formalizado, por exemplo, na Constituição Brasileira, aludida tanto pelos defensores quanto pelos opositores das cotas.

[...] é imprescindível que adotemos o princípio da eqüidade, ou seja, tratar diferentemente aqueles que são diferentes para se chegar à igualdade de oportunidades. [...]

[...] As Cotas não vão acirrar de forma alguma o racismo, mas sim é uma ação concreta dos valores de igualdade bem claros na Constituição de 1988, pró-ativa na sua afirmação de que é necessário adotar mecanismos capazes de viabilizar a igualdade almejada [...]

[...] Apesar de concordar que temos uma dívida histórica com nossos irmãos negros, a reserva de cotas fere o $l^{\circ}$ direito constitucional que reza que "Todos somos iguais perante a lei, independente de cor, raça, religião ou sexo" [...]

Vale lembrar que a polêmica sobre o estabelecimento de cotas raciais ferir ou não os princípios constitucionais não se restringe ao grupo de professores

9 Dentro dessa perspectiva encontramos autores como Yvonne Maggie, Peter Fry, Célia Azevedo e Marcos Chor Maio, entre outros. 
pesquisados, mas está posta, hoje, na arena jurídica, dividindo especialistas, políticos e militantes de ambos os lados.

Ao lado da defesa de políticas universalistas centradas na melhoria da educação pública para todos, encontramos também inúmeros professores que defendem a instituição de cotas sociais - para pobres ou para alunos oriundos de escolas públicas. Os argumentos para a defesa de cotas sociais centram-se, por um lado, na idéia de que estas beneficiariam automaticamente os estudantes negros, sem 0 incômodo de lidar com critérios raciais. E, por outro lado, enfatizam uma preocupação com parcelas da população que, embora excluídas socialmente, não seriam beneficiadas com as cotas raciais, especialmente os "brancos pobres".

[...] Defendo a cota para alunos de escolas públicas e acredito que esta aumentará em consequiência o numero de negros nas universidades, pois sabemos que em nossas escolas públicas mais carentes a maioria são negros.[...]

[...] É preciso promover muito mais uma inserção sócio-econômica das pessoas pobres, do que apenas a inserção de pessoas negras. [...]

[...] Uma solução de curto prazo é a adoção de quotas, não para grupos étnicos, mas para estudantes do ensino público [...]

[...] Mas as vezes fico me perguntando: será que se estabelecesse cota social já não estaríamos contemplando a maioria negra que vive as margens da sociedade? Será que o pobre branco não esta sendo deixado de lado?[...]

Em alguns casos, a condenação das cotas raciais - não apenas nas universidades, mas também em concursos públicos - vem acompanhada de um profundo sentimento de injustiça, como se pode perceber pelo tom de desabafo da professora que nos diz:

Fiz um concurso em Contagem, concorrendo com pessoas negras que estudaram na mesma faculdade que eu. Algumas dessas pessoas tiveram uma pontuação menor que a minha e já foram nomeadas. Que justiça é essa? Se freqüentamos a 
mesma escola, concordam que teríamos de usufruir das mesmas chances? Por que então terem mais direitos que eu?

A fala da professora nos remete a duas questões centrais na polêmica das cotas: de um lado, o ressentimento causado entre aqueles que, cientes de seu lugar de excluídos na sociedade brasileira, vêem nas cotas raciais mais um mecanismo de exclusão; de outro lado, a discussão em torno da idéia de mérito individual. Sobre 0 primeiro ponto, Guimarães (2005: 176) reconhece que esse é um dos argumentos utilizados para a condenação das cotas raciais: "alienam dos negros possíveis aliados brancos, sobretudo entre a classe operária e entre os liberais". As ponderações sobre o risco de se cometer injustiças contra brancos pobres e demais grupos não beneficiados não podem ser vistas, assim, apenas como indícios do não reconhecimento do racismo ou da busca de privilégios para outros grupos. Há que se levar em consideração os temores de outros grupos que também sofrem com mecanismos históricos de exclusão e injustiça social.

Outra questão que emerge no depoimento acima e que se evidenciou na fala de inúmeros professores está associada ao argumento do mérito individual, cujos fundamentos parecem assentar-se em uma concepção liberal pautada no individualismo e na competição. Para alguns, o acesso às universidades deve obedecer a parâmetros estritos de capacidade do indivíduo, sob o risco de se comprometer a qualidade do ensino superior, e o estabelecimento de cotas é visto como uma interpelação desses princípios.

Em inúmeros depoimentos contrários às cotas, os professores fizeram questão de afirmar que não acreditam em uma menor capacidade dos negros, reafirmando, assim, uma concepção de que o ingresso por meio de cotas seria uma forma de atestar a não capacidade. Além de contrariar a seleção pelo mérito, as cotas raciais, de acordo com alguns professores, poderiam alimentar os mecanismos de inferiorização do negro na sociedade, fomentando ainda mais o preconceito, ao invés de combatê-lo.

Ser negro nãoéser deficiente enem precisar de tratamento diferenciado. Acho que tudo é uma questão de princípio, ou melhor, na oportunidade de uma formação igual a todos, o que possibilitará o nivelamento das condições de acesso à uma vaga na universidade. Esta atitude de reservar vagas para os negros estará acentuando o preconceito já existente. 
Quando aceita participar de um sistema de cotas, o negro está se denominando inferior, portanto incapaz de concorrer, seja a uma vaga em um concurso, seja a uma vaga na universidade, com um branco.

Se querem que se aumente o número de negros nas universidades, o melhor, a médio prazo seria garantir um pré-vestibular gratuito onde ele poderia aprender tudo o que ainda não aprendeu e competir nas mesmas condições de igualdade com os demais candidatos sem se sentir desmerecido por estar ali. Saber que conseguiu entrar em uma universidade por méritos próprios, eleva a auto-estima de qualquer cidadão.

Alguns dos defensores das cotas raciais postulam, entretanto, que "políticas afirmativas visam corrigir, e não eliminar, mecanismos de seleção por mérito, e garantir o respeito à liberdade e à vontade individuais" (Guimarães, 2005: 175), o que explicaria, inclusive, a oposição por parte de alguns setores da esquerda, que questionam a própria meritocracia e individualismo aí presentes.

Outro ponto que emergiu com muita frequiência, sobretudo entre os professores que posicionaram-se contrariamente ao estabelecimento de cotas, refere-se à dificuldade em se identificar quem seriam os beneficiários dessa política em um país profundamente miscigenado como 0 nosso.

[...] não existe uma forma objetiva de determinar se uma pessoa é branca ou negra, sobretudo numa população como a brasileira, muito miscigenada. [...]

[...] 0 aspecto prático dessa situação, é que é um ponto de reflexão importante: Como num país de alta miscigenação de raças, provar quem realmente é negro e ter direito as cotas? Como não ser injusto com os descendentes afro-brasileiros que não tem a pele negra, ou que tem na sua certidão de nascimento outra denominação para sua cor? [...]

A idéia de que somos todos afro-descendentes e de que o longo processo de miscigenação inviabilizaria uma separação objetiva entre "brancos" e "negros", aparece, muitas vezes, como indício de um certo "orgulho nacional" por sermos um só povo, uma só "raça". 
[...] 0 Brasil é um país formado por um povo diverso, negros, brancos e índios, e da mistura entre estas raças que surgiram: o cafuzo, o mulato e o caboclo. Portanto 0 Brasil não é branco, nem negro e nem indígena. e sim "multicolorido". [...]

[...] nós estudamos que o povo brasileiro, praticamente sem exceção tem no sangue a raça negra. Concluímos então, que a maioria de nós somos também negros. [...]

Se, por um lado, podemos nos perguntar se tais concepções remetem a uma crença no velho conhecido mito da democracia racial, por outro lado, devemos tomar cuidado com uma associação automática entre valorização da mestiçagem e crença na democracia racial. Como nos lembra o antropólogo Hermano Viana (2004), "criamos o mito de que para combater o nosso racismo devemos, entre outras coisas, deixar de valorizar o fato de sermos um povo mestiço. [...] Aquela coisa do bebê e da água do banho: para se livrar do mito da democracia racial jogamos fora a valorização da mestiçagem."

Em meio a tantos questionamentos acerca da identidade étnico-racial dos brasileiros, alguns professores também explicitaram sua preocupação com uma identificação forjada em função de interesses imediatos e oportunistas.

[...] Se qualquer pessoa pode se auto declarar negra em prol de um benefício, muitos podem fazê-lo sem ter esse direito. Acho que se deveriam estabelecer critérios mais seletivos que realmente atenda a quem precisa.[...]

[...] Neste ano mesmo, em uma designação de vagas de um concurso, pude presenciar pessoas de minha convivência e que nunca se importaram ou se disseram negras até o presente momento, se utilizarem desta brecha para terem vantagens: se intitularam como negras, podendo assim alcançar vagas que talvez sem este título, não fosse possível.[...]

0 temor de muitos transforma-se, entretanto, em argumentos favoráveis para outros. Ou seja, o risco de tais políticas "forjarem" uma identidade negra em alguns indivíduos é apontado como um dos pontos positivos das políticas afirmativas. 
[...] Penso que o tempo fará com que as listagens de negros e pardos de concursos de vestibulares, tenham a mesma quantidade de nomes que a listagem principal, e isto será a amostra que o Brasil se assume como Afro-descendente, enfraquecendo o preconceito e a discriminação. [...]

[...]Ressalto como positivo o resgate da identidade sempre negada dos negros, que em meio a estas questões se apresenta como co-autor de sua história[...]

Levando-se em conta que a ideologia do branqueamento, forjada na passagem do século XIX para o XX, ainda encontra-se bastante arraigada na sociedade brasileira, alguns apontam a discussão e implementação das cotas raciais como uma boa oportunidade para se inverter os pólos da equação. Ou seja, pela primeira vez, tornar-se negro, assumir-se como negro, pode representar 0 alcance de algum benefício social, fato inédito em nossa história.

A questão da constituição de uma identidade negra, apontada por muitos como uma das - ou até mesmo a principal - maneiras de se combater o racismo, é também um dos pontos mais rebatidos pelos que se colocam contrários ao estabelecimento de cotas. Entre os argumentos apresentados, ressalta-se 0 perigo de se congelar as identidades étnico-raciais dos indivíduos em dois únicos pólos: "negros" e "brancos", ignorando-se o mosaico de definições que demarcam as identidades étnico-raciais em nosso país - ou mesmo desqualificando-o, ao associá-lo estritamente ao mito da democracia racial, como vimos anteriormente.

A esse respeito, Yvonne Maggie (2005) nos lembra que:

Tentamos, no Brasil, ao longo do século XX, construir uma sociedade na qual os indivíduos podiam transitar entre marcas ou até mesmo não se pensar a partir delas. 0 que essas políticas estão propondo é o fim dessa possibilidade e o início de uma marcação muito rígida de indivíduos, que não poderão mais dizer que, tão-somente, pertencem à raça humana.

Assim, para além do perigo de uma bipolarização das identidades étnicoraciais, um dos pontos centrais da discórdia diz respeito ao próprio processo de racialização da população, que teria de ser necessariamente operado para 
viabilizar a identificação dos beneficiários de uma política de cotas. A esse respeito, Azevedo (2004) pondera que:

Se a raça foi uma invenção danosa aos destinos da humanidade, tal como reconhecem muitos defensores da cota racial, por que reivindicar a racialização pelo Estado? [pois] para que o triunfo da raça seja completo é preciso antes construir a figura de um "povo negro brasileiro" cujos interesses e valores monolíticos apontam para uma identidade racial tão essencializada em termos sociológicos quanto um dia ela foi pensada em termos biológicos." [...] 0 combate ao racismo significa lutar pela desracialização dos espíritos e das práticas sociais. Para isso é preciso rechaçar qualquer medida de classificação racial pelo Estado com vistas a estabelecer um tratamento diferencial por raça [...].

No contraponto desses argumentos, e assumindo uma postura mais radical em defesa de um "racialismo anti-racista", Guimarães (2005: 67) nos diz que "se os negros considerarem que as raças não existem, acabarão também por achar que eles não existem integralmente como pessoas, posto que é assim que são, em parte, percebidos e classificados por outros".

É também esse "lugar social" que está em jogo, quando se recorre ao argumento de que a chegada de mais indivíduos negros em postos elevados da hierarquia social "provêem role models de êxito profissional para negros que, de outro modo, não teriam em quem se espelhar na busca de ascensão social" (Guimarães, 2005: 181). Este argumento foi identificado na fala de apenas dois professores. Um deles nos diz que :

[...] precisamos de ações afirmativas já, para que tenhamos representatividade significativa de negros em todos os segmentos sociais como igrejas, hospitais, shoppings, aeroportos, eventos de moda, mídia, telenovelase que esses ocupem lugares privilegiados e não somente em funções subalternas como acontece atualmente.[...]

Mas há, também, os que ponderam sobre o benefício atingir exclusivamente uma classe média negra, mantendo intocado o problema da população mais pobre: 
[...] acredito que isso não assegura a inclusão de quem realmente precisa. Uma vez que o negro com formação básica em escolas particulares terão mais chances que o negro que é excluído pela sua cor, e principalmente, pela sua posição social.

Alguns autores lembram o exemplo dos EUA para confirmar a problemática exposta:

No imenso debate sobre o sucesso ou fracasso das políticas de ação afirmativa, que se desenrolou na última década nos Estados Unidos, há uma afirmativa constante, reconhecida até mesmo pelos defensores da cota racial: as políticas de ação afirmativa beneficiaram sobretudo pessoas pertencentes à classe média negra, deixando intocado o problema da pobreza da maior parte da população negra americana. (Azevedo, 2004)

0 argumento mais utilizado por aqueles que se posicionaram favoravelmente ao estabelecimento de cotas foi aquele que diz respeito à reparação pelas injustiças causadas aos africanos e seus descendentes, ao longo da história brasileira. Foi sobretudo no âmbito de falas pautadas neste argumento que pudemos identificar, mais claramente, a mobilização de saberes específicos sobre a história africana e afro-brasileira, com diversos professores recorrendo a dados históricos, conceitos e indicação de bibliografia pertinente ao tema.

[...] Veio como escravo exercer a força de trabalho em um Brasil colônia portuguesa. Ajudaram a construir a grande nação brasileira e enriqueceram outros em troca de nada, passaram por vários episódios... Da escravidão até os dias de hoje. Mas, o problema aflora quando analisamos sua realidade social, econômica e política nos dias de hoje. Tal como outros tantos brasileiros, o quadro continua desumano, não a escravidão institucionalizada do Brasil colônia, mas uma "escravidão social" enjaulada pela miséria e a exclusão; e ainda sofre o "racismo à brasileira".[...]

Sabemos que o Brasil tem uma dívida com os negros, basta recorrermos à história para relembrarmos que no início do século XIX surgiram os primeiros cursos superiores, sendo que em 1872, o país registrava a existência de leis que proibiam o acesso de negros livres ou forros a qualquer nível de escolaridade. Há 
120 anos que a escravidão foi abolida, mas a elite continua branca em um país onde a maioria é pobre e negra.[...]

Outro argumento mobilizado pelos que se posicionaram favoravelmente coaduna-se com a hipótese levantada no início deste trabalho: a de que 0 surgimento do tema "cotas" no cenário nacional vem proporcionando uma significativa ampliação do debate sobre a questão racial, em nosso país. Essa parece ter sido a aposta de alguns professores, que nos disseram:

[...]As cotas para alunos negros nas universidades vieram para que tomemos consciência do longo caminho que vem sendo conquistado pelo povo negro e por uma sociedade que busca realmente cidadania a todas as pessoas. [...]

A criação do sistema de cotas abriu uma discussão nacional sobre as desigualdades sociais no Brasil. Acredito que é muito importante toda a sociedade participar desses debates, só assim encontraremos solução para o problema de desigualdade social no Brasil. Discutindo, criaremos políticas públicas concretas e ações afirmativas não só para o afro-descendente mas também para o índio, os pobres e miseráveis deste país. [...]

Este talvez seja, efetivamente, o maior ganho contabilizado até 0 momento. 0 debate sobre as cotas vem extrapolando as instâncias tradicionalmente envolvidas com a discussão da temática racial, em nosso país, para incluir novos sujeitos, cujas vozes contribuem para desestabilizar algumas das certezas construídas historicamente acerca do lugar dos afrodescendentes em nossa sociedade, ao mesmo tempo em que possibilita que novos ingredientes sejam acrescidos ao complexo processo de identificação étnico-racial dos brasileiros.

\section{Saberes docentes na discussão sobre cotas raciais: algumas considerações}

0 material empírico analisado neste trabalho trouxe evidências de que ao se posicionarem sobre o tema das cotas raciais, os professores que atuam em um sistema público de ensino explicitam saberes e representações sobre a 
população negra, a educação pública e a sociedade, reinterpretando alguns dos argumentos presentes no debate nacional sobre o racismo e as políticas de valorização dos afro-descendentes. Fazem isso a partir de seu lugar social, das condições históricas e sociais de sua profissão, mobilizando saberes diversos, provenientes de diferentes instâncias de formação.

Trabalhando com a idéia de que estes professores constituem-se como sujeitos sócio-culturais, com uma identidade multifacetada e cuja formação é realizada em múltiplos tempos e espaços, torna-se importante considerar que seus posicionamentos, saberes e representações são fruto de experiências pessoais, sócio-culturais, de formação e profissionais (TARDIF, 2002; TARDIF e LESSARD, 2005). Dentro do pressuposto de que o exercício da profissão em uma instituição escolar é um dos elementos que singulariza a condição e ofício de professor (TEIXEIRA, 1996), tal trabalho traz também algumas evidências para se pensar a imagem que estes professores têm de seu local de trabalho e do público com o qual lidam, assim como a relação que estabelecem com instâncias de legitimação e ingresso na profissão (onde emerge a questão das cotas em concursos públicos, por exemplo).

Assim, ao refletirem sobre as cotas, os professores mobilizam saberes provenientes de suas experiências familiares e escolares, recorrem a dados históricos e conceitos aprendidos em sua formação acadêmica e sistematizam saberes provenientes de sua experiência profissional, expressos na avaliação que fazem de seus alunos, de como pensam que estes se sentiriam ao se beneficiarem de cotas raciais, da maneira como isso poderia afetar sua autoestima e as conseqüências de tudo isso para o combate ou acirramento de preconceitos no seio da sociedade brasileira.

Os saberes relativos à temática africana e afro-descendente mobilizados pelos professores, assim como o exercício da argumentação por eles vivenciado, demandam uma análise mais aprofundada, que extrapola os objetivos e limites da análise preliminar apresentada neste texto, mas que podem trazer importantes contribuições para estudos que se debruçam sobre os saberes e representações de docentes e sua relação com os processos de formação continuada de professores. 


\section{Referências}

AZEVEDO, Celia Maria Marinho de. Cota racial e estado: abolição do racismo ou direitos de raça? In: Cadernos de Pesquisa, v. 34, n. 121, jan./abr. 2004.

GUIMARÃES, Antonio Sérgio Alfredo. Racismo e anti-racismo no Brasil. São Paulo: Fundação de Apoio à Universidade de São Paulo; Ed. 34, 2005 (2ª edição revista).

MAGGIE, Yvonne. Políticas de cotas e o vestibular da UnB ou a marca que cria sociedades divididas. Horizontes Antropológicos. vol.11 no.23 Porto Alegre Jan./June 2005.

MAGGIE, Yvonne; FRY, Peter. A reserva de vagas para negros nas universidade brasileiras. Estudos Avançados. vol.18 nº.50 São Paulo, 2004.

MATTOS, Hebe Maria 0 ensino de História e a luta contra a discriminação racial no Brasil. In: ABREU, Martha; SOIHET, Rachel (orgs.). Ensino de História: conceitos, temáticas e metodologia. Rio de Janeiro: Casa da Palavra, 2003.

SANTOS, Sales Augusto (org.). Ações afirmativas e combate ao racismo nas Américas. Brasília: ministério da Educação, Secretaria de Educação Continuada, Alfabetização e Diversidade, 2005. (Coleção Educação para todos).

SCHWARCZ, Lilia Moritz. Nem preto nem branco, muito pelo contrário: cor e raça na intimidade. In: SCHWARCZ, Lilia Moritz (org.) História da vida privada no Brasil: contrastes da intimidade contemporânea. São Paulo Companhia das Letras, 1998.

SCHWARCZ, Lilia Moritz. Racismo à brasileira. In: Ensino de História e Cultura africana e afro-brasileira - Livro-texto (vários autores). Belo Horizonte: PUC Minas Virtual, 2006.

TARDIF, Maurice. Saberes docentes \& formação profissional. Petrópolis, RJ: Vozes, 2002.

TARDIF, Maurice; e LESSARD, Claude. O trabalho docente: elementos para uma teoria da docência como profissão de interações humanas. Petrópolis, RJ: Vozes, 2005.

TEIXEIRA, Inês Castro. Os professores como sujeitos sócio-culturais. In: DAYRELL, Juarez (org.). Múltiplos olhares sobre educação e cultura. Belo Horizonte: UFMG, 1996.

VIANA, Hermano. Mestiçagem Fora de Lugar. Folha de São Paulo, Caderno Mais, 27/06/ 2004. 


\section{What says teachers about affirmative actions program in the public university}

\section{ABSTRACT}

This work shows a anlysis the opinion, representation and knowledges about the affirmative actions program to afro-descendent wich had expressed by the group of public scholl teachers in the internet forum. First, we introduce a short overview about the racial problem in Brazil, after that we indentify and analysis the arguments wich was used by the teachers.

Key-words: representations, affirmative actions program; anti-racist education. 